\title{
What have we learned from observational studies and clinical trials of mild to moderate COPD?
}

\author{
Miriam Barrecheguren ${ }^{1}$, Cruz González ${ }^{2}$ and Marc Miravitlles ${ }^{1 *}$ (1)
}

\begin{abstract}
Chronic obstructive pulmonary disease (COPD) is a major cause of morbidity and mortality worldwide. It is well established that patients with mild to moderate disease represent the majority of patients with COPD, and patients with mild COPD already have measurable physiological impairment with increased morbidity and a higher risk of mortality compared with healthy non-smoking individuals. However, this subpopulation is both underdiagnosed and undertreated. In addition, most clinical trials include cohorts of patients with worse lung function and quality of life, which are very different from the milder patients usually seen in primary care.

Clinical trials have shown that mild-moderate COPD patients present an improvement in lung function after treatment with long-acting bronchodilators (LABD). Inhaled therapy has also shown benefits in terms of symptoms, health-related quality of life (HRQL) and exacerbation prevention in this population. Early intervention might have also a positive effect to prevent functional impairment. Nevertheless, there is scarce evidence from randomised clinical trials and real-life studies about the importance of pharmacological treatment in early stages of COPD to improve long-term outcomes. New concepts such as clinically important deterioration may help to investigate the impact of interventions on the natural history of the disease.
\end{abstract}

Keywords: COPD, Diagnosis, Epidemiology, Guidelines, Mild-moderate disease, Physical activity, Quality of life, Treatment

\section{Background}

Chronic obstructive pulmonary disease (COPD) is characterised by chronic airflow limitation, which is usually progressive. This disease is a major cause of morbidity and is currently the fourth leading cause of death worldwide $[1,2]$. Although it is mostly related to exposure to tobacco smoking, patients exposed to biomass and pollution are also at risk of developing COPD.

The impact of COPD on each patient depends on the degree of airflow limitation, the severity of symptoms and comorbidities. The Global Initiative for Chronic Obstructive Lung Disease (GOLD) staging system categorises COPD into 4 severity stages (based on post-bronchodilator FEV1): stage I or mild, FEV1 $\geq 80 \%$ predicted; stage II or moderate, FEV $1 \geq 50 \%$ and $<80 \%$ predicted; stage III or severe, FEV $1 \geq 30 \%$ and $<50 \%$ predicted; and stage IV or very

\footnotetext{
* Correspondence: mmiravitlles@vhebron.net

'Pneumology Department, Hospital General Universitari Vall d'Hebron, CIBER de Enfermedades Respiratorias (CIBERES), P. de la Vall d'Hebron, 119-129, 08035 Barcelona, Spain

Full list of author information is available at the end of the article
}

severe, FEV1 $<30 \%$ predicted [3]. As the disease progresses, there is greater restriction in daily activity with impaired quality of life and an increase of symptoms and exacerbations.

Nonetheless, the reduction in daily activity is already present in mild disease [4]. Since COPD is progressive, it is important to identify and treat patients at early stages in order to prevent further deterioration. Patients with mild (stage I) COPD already have measurable physiological impairment with increased morbidity and a higher risk of mortality compared with healthy non-smoking controls [5]. It is well established that patients with mild to moderate disease represent the majority of patients with COPD [6]. However, this subpopulation is both underdiagnosed and undertreated [7]. In addition, most clinical trials include cohorts of patients with worse lung function and worse quality of life, which are very different from those usually seen in primary care (PC) [8].

Encouragement of smoking cessation, in conjunction with management of symptoms and treating activity limitations and exacerbations by appropriate pharmacologic 
and non-pharmacologic management at the earliest possible stage can positively affect the impact and progression of the disease [9]. In recent years, newer strategies and a growing number of new pharmacologic agents to treat COPD have also been introduced and show promise in improving the management of COPD [10]. New disease lung models to predict patient-specific drug deposition are also being developed in order to individualise therapy [11].

The aim of this article is to review the current evidence on the epidemiology, natural history and management of mild to moderate COPD (defined as an FEV1 $>50 \%$ predicted), highlighting the importance of treatment in earlier stages of the disease to try to prevent progression.

\section{Epidemiology and natural history}

The World Health Organization estimates that up to 328 million people around the world have COPD with a global prevalence of 1\% [12]. This prevalence increases to $8-10 \%$ for individuals above 40 years old [13]. A recent systematic review aimed at estimating the prevalence of COPD across world regions among people aged 30 years or more found an overall prevalence of $10.7 \%$ in 1990, which increased to $11.7 \%$ in 2010 (14.3\% in men and $7.6 \%$ in women) [14]. However, the prevalence of COPD varied widely among world regions, being the highest in the American region (14.1\%), and the lowest in South East Asia (7.8\%) [14]. This variability might be explained by differences in exposures and environmental and genetic factors. Indeed, according to the BOLD study, conducted at 12 sites around the world $(n=8775)$, the overall prevalence of COPD ranged from 11.4 to
26.1\%; the prevalence of GOLD I being between 1.4$15.5 \%$ and the prevalence of GOLD II between 5.1 and 12.4\% [6]. The Latin American Project for the Investigation of Obstructive Lung Disease (PLATINO) examined the prevalence of COPD in adults $>40$ years of age and reported crude rates of GOLD stage I between 5.2 and 12.5\% and GOLD II between 1.9 and 6.4\% in five Latin American countries [15]. Another systematic review estimated a pooled prevalence for GOLD I of 9.8\% (95\% confidence interval (CI) 5.9-15.8) and of 5.5\% for GOLD II (95\%CI 3.3-9.0) [13].

In Europe, a systematic review by Atsou et al. [16] found a prevalence of COPD from 2.1 to $26.1 \%$ depending on the country, the age group and the methods used, the majority being GOLD I and II.

In Spain, the IBERPOC study conducted in 1997 showed a mean prevalence of COPD of $9.1 \%$ in subjects between 40 and 69 years of age [17]. Ten years later, the EPI-SCAN trial estimated a prevalence of $10.2 \%$ in subjects between 40 and 80 years of age [18]. A sub-analysis of these studies reported an increase of patients in milder stages over time, ranging from $38.3 \%$ for mild and $39.7 \%$ for moderate in the 1997 study to $85.6 \%$ for mild and $13.0 \%$ for moderate in the 2007 study [19]. Despite the wide variability of the results found in these population-based studies, the majority of the patients diagnosed had mild or moderate COPD, independently of the classification criteria used (Table 1).

One of the main concerns in COPD is underdiagnosis, which is more marked in early stages of the disease. It has been estimated that $73-78 \%$ of patients with GOLD stages I-II COPD remain undiagnosed [18]. Llordés et al.

Table 1 Prevalence of COPD GOLD I and II in some epidemiological studies of COPD

\begin{tabular}{|c|c|c|c|}
\hline \multirow[t]{2}{*}{ Study } & \multirow[t]{2}{*}{ Country } & \multicolumn{2}{|l|}{ Prevalence (\%) } \\
\hline & & GOLD I & GOLD ॥ \\
\hline \multirow[t]{2}{*}{ Halbert et al. [13] } & Worldwide & All $7.6(6.0-9.5)$ & \\
\hline & & $9.8(5.9-15.8)$ & $5.5(3.3-9.0)$ \\
\hline \multirow[t]{6}{*}{ Buist AS, et al. (BOLD) [6] } & Guangzhou & $5.9 \%$ & $7.6 \%$ \\
\hline & Salzburg & $16.3 \%$ & $9.3 \%$ \\
\hline & Cape town & $6.5 \%$ & $14.2 \%$ \\
\hline & Reykjavik & $9.7 \%$ & $6.7 \%$ \\
\hline & Krakow & $14.4 \%$ & $10.3 \%$ \\
\hline & Manila & $0.9 \%$ & $11.3 \%$ \\
\hline \multirow[t]{5}{*}{ Menezes AM, et al. (PLATINO) [15] } & Sao Paulo & $10.1 \%$ & $4.6 \%$ \\
\hline & Santiago & $11 \%$ & $4.9 \%$ \\
\hline & Mexico City & $5.2 \%$ & $1.9 \%$ \\
\hline & Montevideo & $12.5 \%$ & $6.4 \%$ \\
\hline & Caracas & $6.4 \%$ & $4.9 \%$ \\
\hline \multirow[t]{2}{*}{ Miravitlles M et al. (EPISCAN) [18] } & Spain & All $10.2 \%$ & \\
\hline & & $5.7 \%$ & $3.9 \%$ \\
\hline
\end{tabular}


carried out a study to quantify the rate of underdiagnosis and the accuracy of COPD diagnosis in PC [20]. The study included 1738 subjects over the age of 45 with a history of smoking and found a rate of underdiagnosis of $73 \%$. Recently, the same group performed a case-finding study in smokers or former smokers older than 40 years and found a prevalence of COPD of $26.7 \%$, with the majority of patients being in GOLD stages I and II (42.1 and $49.1 \%$, respectively) [21]. Up to $29 \%$ of patients with underdiagnosed COPD are asymptomatic [22], which contributes to late detection. In addition, patients often under-recognize the significance of respiratory symptoms, or they may accept that their symptoms are caused by smoking and ignore them rather than consult. Another cause for underdiagnosis might also be a deficient active search for COPD by health care professionals [21]. Some of the diagnostic initiatives that have been tested to improve COPD diagnosis are early detection programs [23] and other tools such as the use of peak-flow meters or mini spirometers [24], and screening questionnaires $[21,25]$.

In contrast to underdiagnosis, the definition of COPD based on FEV1/FVC instead of lower limit of normality (LLN) might lead to the overdiagnosis of mild COPD in individuals older than 65 years old [26].

The natural history of COPD is usually described by the rate of decline in lung function. The rate of decline in FEV1 in GOLD stages I-II is faster than in patients with stages III-IV [27-29]. Recently, in a cohort of smokers and ex-smokers, the COPD Gene group showed that functional alteration of the small airways measured by computerized tomography was significantly associated with a decline of FEV1, particularly in mild to moderate stages of the disease, and this association was also evident even before the detection of obstruction in the spirometry [30].

Exacerbations have a negative impact on the natural history of COPD, and their presence has been associated with a faster decline of FEV1, in particular in GOLD stagesI and II [31], in which the effect of each exacerbation on rate of FEV1 decline has been estimated to be $23 \mathrm{ml} /$ year in GOLD 1 and $-10 \mathrm{ml} /$ year in GOLD 2 for any exacerbation, increasing up to $-87 \mathrm{ml} /$ year and $-20 \mathrm{ml} /$ year for GOLD 1 and 2 respectively for each severe exacerbation. Frequent exacerbators also have a worse quality of life and an increased risk of death [32-34]. Thus, the prevention of exacerbations should be a target for every COPD patient, irrespective of the severity of the disease.

\section{Symptoms, quality of life and physical activity}

COPD is defined by the presence of chronic respiratory symptoms, among which exertional dyspnoea, cough and sputum production are the most frequent [35].
Although more severe patients present a higher intensity of symptoms, there is not always a clear relationship between the degree of airflow obstruction and the presence and impact of respiratory symptoms in a patient with COPD $[35,36]$. The observational study ASSESS characterised the symptoms of COPD during $24 \mathrm{~h}$ and assessed their relationship with patient-reported outcomes [37]. The analysis showed that the frequency of symptom occurrence was high for any degree of bronchial obstruction, with a prevalence of symptoms in GOLD stages I-II of $84-88 \%$.

The presence of respiratory symptoms in patients with early COPD may modify long-term FEV1 decline and health-related quality of life. Symptomatic subjects with GOLD I COPD have a more rapid long-term decline in lung function than asymptomatic subjects [38, 39].

Despite referring fewer symptoms, mild COPD patients present exercise limitation that leads to changes in lifestyle and deconditioning, with an increasing burden of the disease beyond the degree of airflow obstruction. Indeed, around two thirds of GOLD stage II patients may have significant lung hyperinflation [40]. This hyperinflation is manifested as exertional dyspnoea, and furthermore, dyspnoea significantly contributes to a worse quality of life due to the high impact on their daily activities [41]. Even mild patients may have severe dyspnoea; a study carried out in 5299 subjects found that 7.5 and $18.3 \%$ of subjects with GOLD stages I and II, respectively, had a Medical Research Council (MRC) score $\geq 3$ [42]. Similarly, a large European observational study conducted in 1817 patients in PC showed a high prevalence of symptoms in GOLD II patients (cough $76.6 \%$, sputum $64.1 \%$, and dyspnoea $67.3 \%$ ). Moreover, $31 \%$ had a MRC dyspnoea grade $\geq 3$. [43]. In a recent analysis carried out in 49,438 COPD patients, $50.2 \%$ were GOLD stage II, and $37.1 \%$ had a MRC dyspnoea grade $\geq 3$, demonstrating that significant dyspnoea can be present in early stages of the disease [44]. In addition to being the most frequent symptom, dyspnoea has proven to be a better predictor of death at 5 years than airway obstruction in patients with COPD [45].

Concerning quality of life, the study by Jones et al. [43] using the St. George's Respiratory Questionnaire [SGRQ] and the 12-Item Short Form Survey [SF-12] demonstrated that GOLD I and II patients had an impaired quality of life compared with healthy individuals. These results are similar to those obtained in the EPI-SCAN study, which observed a significant impairment of health-related quality of life in all severities of COPD, even GOLD I and II and undiagnosed COPD patients [18].

Physical activity significantly deteriorates in patients with COPD as the disease progresses [46], and the reduction in physical activity is one of the best predictors 
for COPD survival [47]. In addition, physical inactivity is strongly associated with the presence of comorbidities [48]. In contrast, regular physical activity reduces hospitalisation and the risk of death in COPD [49]. However, even in early stages of the disease, most patients with COPD spend less time walking (and walking more slowly) and standing, and more time sitting and lying compared with sedentary healthy elderly subjects [50].

\section{Treatment of mild to moderate COPD}

The main objectives for the treatment of COPD are the reduction of symptoms, the reduction of frequency and severity of the exacerbations and the improvement of prognosis $[3,51]$. Non-pharmacological treatment, especially smoking cessation, is essential for every COPD patient and ha sproven to be the most efficient and cost-effective therapeutic strategy [3, 51]. Smoking cessation slows the loss of lung function and improves survival. Indeed, the benefits may be more evident in milder patients than in individuals with a more established disease [52]. Psychotherapy might be beneficial in addition to exercise and medication. Other non-pharmacological approaches include regular physical activity, an adequate nutrition status, management of comorbidities, and vaccination against pneumococcal and influenza viruses is also recommended for all patients. Pulmonary rehabilitation has shown to improve symptoms, exercise tolerance and health-related quality of life, and to reduce the risk of morbidity from acute exacerbations of COPD [53]. Both a meta-analysis and a systematic review concluded that patients with mild to moderate COPD also benefit from short- and long-term rehabilitation [54, 55]. Hence, considering the benefits of physical activity, patients with COPD should be encouraged to increase their level of exercise from early stages.

Real-life experience of treatment of mild-moderate COPD Mild COPD patients are frequently followed in a PC setting, and they are usually not included in randomised controlled trials (RCT) [8], therefore, database studies could provide interesting data on the management of these subjects. An analysis of real-life prescribing patterns in primary care in the UK described the treatment of 24,957 COPD patients among which half were GOLD II [56]. Up to $17.7 \%$ did not receive any treatment for their disease, and $14 \%$ were treated only with short-acting $\beta$-agonists (SABA) despite being symptomatic. In fact, two thirds of the untreated patients referred a COPD Assessment Test (CAT) score > 10 , while $22.7 \%$ had a modified $M R C \geq 2$, consistent with highly symptomatic disease. Moreover, a high percentage of treated patients remained symptomatic: $36.6 \%$ of patients had a modified MRC $\geq 2$, and $76.4 \%$ had a CAT score $\geq 10$ with their current treatment regimen.
In a similar study that included 7881 newly diagnosed COPD patients in PC, $54.3 \%$ had GOLD stage II at the time of diagnosis. Initially, 37.9\% were treated only with short-acting bronchodilators (SABD) or did not receive any inhaled treatment, while only one third of the patients were prescribed a long-acting bronchodilator (LABD), alone or in combination with inhaled corticosteroids (ICS) [57]. Raluy-Callado et al. [58] described the treatment patterns in a population of prevalent and incident COPD patients, of whom 53.5 and 61\% were GOLD stage II, respectively. The authors found that almost half of the incident patients with FEV1 $>50 \%$ and infrequent exacerbations were prescribed monotherapy, being SABD the most frequent (29.3\%) [58]. Similar results have been observed in other countries. In Catalonia (Spain), a recent study showed that $55.2 \%$ of the patients diagnosed in PC had GOLD stage II COPD. After the diagnosis of the disease, GOLD II patients frequently remained untreated $(28.1 \%)$ or were treated only with a SABD (18.5\%) [59].

The reasons for undertreatment are varied. COPD patients often do not seek medical help until the symptoms interfere with their daily life, and asymptomatic patients are also less likely to be identified and to receive treatment. In addition, some patients tend to reduce their physical activity even at early stages of the disease, which might help to minimize symptom perception. Moreover, mild COPD patients are more likely to experience unreported exacerbations [60], which may contribute to an underestimation of the impact of COPD. Another possible reason for undertreatment is a lack of awareness of guideline recommendations.

\section{Clinical trials of pharmacological treatment of mild to moderate COPD}

Clinical trials usually include patients with moderate or severe COPD; hence, the data available on the benefits of inhaled treatment in mild COPD patients are limited. This is in contrast with the distribution of severity in a real-life setting, with up to $50 \%$ of the COPD patients controlled in PC being GOLD stage II $[16,59]$. However, there is some evidence of the efficacy of treatments in GOLD stage II COPD patients derived from studies on mild-moderate COPD and subgroup analysis of RCTs (Table 2).

\section{Lung function}

The effects of the treatments are measured by different outcomes: lung function, dyspnoea, quality of life and exacerbations. In terms of lung function, in a 12-week placebo-controlled study conducted in Germany, treatment with tiotropium showed a significant increase of trough FEV1 (+79 ml), which was even more pronounced in COPD patients with a FEV1 between 50 and 
Table 2 Results in GOLD stage II COPD patients in randomised clinical trials

\begin{tabular}{|c|c|c|c|}
\hline Study & Treatment & $\begin{array}{l}\text { GOLD stage } \\
\text { Il patients }(n)\end{array}$ & Results \\
\hline $\begin{array}{l}\text { Decramer M, et al. } \\
\text { UPLIFT study [66] }\end{array}$ & Tiotropium vs. placebo & 2739 & $\begin{array}{l}\text { - Lower rate of decline of mean } \\
\text { postbronchodilator FEV1 } \\
\text { - improvement in the SGRQ } \\
\text { - increase in the time to first } \\
\text { exacerbation }\end{array}$ \\
\hline Beeh KM, et al. [61] & Tiotropium vs. placebo & 586 & - increment in trough FEV1 \\
\hline $\begin{array}{l}\text { Duser D, et al. } \\
\text { Mistral study [68] }\end{array}$ & Tiotropium vs. placebo & 426 & $\begin{array}{l}\text { - reduction in the number of } \\
\text { exacerbations }\end{array}$ \\
\hline $\begin{array}{l}\text { Freeman D, et al. } \\
\text { SPRUCE study [62] }\end{array}$ & Tiotropium & 185 & $\begin{array}{l}\text { - improvement in trough FEV1 } \\
\text { - reduction in the number of } \\
\text { exacerbations }\end{array}$ \\
\hline $\begin{array}{l}\text { Singh D, et al. } \\
\text { OTEMTO study [64] }\end{array}$ & Tiotropium/olodaterol vs. tiotropium or placebo & 1042 & $\begin{array}{l}\text { - improvement in the trough FEV1 } \\
\text { - improvement in symptoms } \\
\text { and the SGRQ }\end{array}$ \\
\hline Vincken W, et al. [88] & Tiotropium vs. ipratropium & 535 & $\begin{array}{l}\text { - improvement in trough FEV1 } \\
\text { - improvement in PEFR, salbutamol } \\
\text { use, TDI, and SGRQ } \\
\text { - reduction in the number of } \\
\text { exacerbations }\end{array}$ \\
\hline Casburi R, et al. [89] & Tiotropium vs. placebo & 921 & $\begin{array}{l}\text { - improvement in trough FEV1 } \\
\text { - reduction in dyspnoea } \\
\text { - improvement in health status scores } \\
\text { - reduction in the number of } \\
\text { exacerbations }\end{array}$ \\
\hline $\begin{array}{l}\text { Jenkins C, et al. } \\
\text { TORCH study [63] }\end{array}$ & SFC vs. placebo & 2156 & $\begin{array}{l}\text { - reduction in the risk of death } \\
\text { - improvements in FEV1 } \\
\text { - reduction in the annual rate } \\
\text { of exacerbations }\end{array}$ \\
\hline $\begin{array}{l}\text { Jones PW, et al. } \\
\text { ISOLDE study [90] }\end{array}$ & Fluticasone propionate vs. placebo & $\begin{array}{l}391 \text { (mild) } \\
359 \text { (moderate-severe) }\end{array}$ & $\begin{array}{l}\text { - reduction in the number of } \\
\text { exacerbations (less in mild disease) }\end{array}$ \\
\hline $\begin{array}{l}\text { Vestbo J, et al. } \\
\text { SUMMIT study [77] }\end{array}$ & $\begin{array}{l}\text { Fluticasone fuorate vs. placebo } \\
\text { vs. vilanterol vs. combination therapy }\end{array}$ & 4135 vs 4121 vs 4118 & $\begin{array}{l}\text { - reduction in the rate of decline in FEV1 } \\
\text { - reduction in the rate of } \\
\text { moderate and severe exacerbation }\end{array}$ \\
\hline $\begin{array}{l}\text { Vogelmeier CF, et al. } \\
\text { CRYSTAL study [65] }\end{array}$ & $\begin{array}{l}\text { Indacaterol/glycopyrronium vs. } \\
\text { LABA/ICS vs. LABA or LAMA }\end{array}$ & $\begin{array}{l}811 \text { vs. } 269 \\
811 \text { vs. } 268\end{array}$ & $\begin{array}{l}\text { - greater improvement on trough FEV1 } \\
\text { - greater improvement in dyspnoea } \\
\text { - greater improvement in health status } \\
\text { - lower rescue medication use }\end{array}$ \\
\hline $\begin{array}{l}\text { Wedzicha JA, } \\
\text { et al. [69] }\end{array}$ & Indacaterol/glycopyrronium vs. SFC & 1680 vs. 1682 & $\begin{array}{l}\text { - superiority in reducing annual rate of exacerbations } \\
\text { - longer time to the first exacerbation }\end{array}$ \\
\hline
\end{tabular}

FEV1 forced expiratory volume in one second, ICS inhaled corticosteroids, LABA long-acting $\beta 2$-agonist, LAMA long-acting muscarinic antagonist, PEFR peak expiratory flow rate, SFC inhaled salmeterol plus fluticasone propionate, SGRQ St George's Respiratory Questionnaire, TDI transition dyspnoea index

$70 \%$ (trough $\mathrm{FEV} 1+113 \mathrm{ml}$ ) [61]. In a PC setting, GOLD I and II patients also showed a trend to improving trough FEV1 with tiotropium compared with placebo after 12 weeks [effect size $40 \mathrm{ml}(95 \% \mathrm{CI}-30,100)$ ] [62].

The efficacy of the inhaled salmeterol/fluticasone combination (SFC) in patients with mild COPD is limited. A post hoc analysis of the TORCH study, which included 2156 subjects with $\mathrm{FEV} 1>50 \%$ showed an increase in FEV1 in GOLD II patients treated with $101 \mathrm{ml}$ of SFC compared with placebo [63].

The combination of a long-acting antimuscarinic agent (LAMA) and a long-acting beta-2 agonist (LABA) (tiotropium/olodaterol) has also shown to improve trough FEV1 compared to placebo $(149 \mathrm{ml}$ versus $-10 \mathrm{ml}$, respectively) in GOLD stage II patients [64]. In the CRYSTAL study, which included 2160 patients with moderate COPD, the effect of the LABA/LAMA indacaterol/glycopyrronium was superior to LABA/ICS in trough FEV1 at week 12 (treatment difference $+71 \mathrm{ml}$ ) and to LABA or LAMA monotherapies (difference + $101 \mathrm{ml}$ ) [65].

\section{Dyspnoea}

Inhaled therapy has also shown benefits in GOLD II patients in terms of symptoms. Treatment with tiotropium/olodaterol improved dyspnoea measured by the Transition Dyspnea Index (TDI) compared to placebo (1.67versus 0.39 ) [64]. The CRYSTAL study also showed 
superior improvement in the total TDI score with indacaterol/glycopyrronium versus LABA/ICS (difference 1.10 units) and versus LABA or LAMA (difference 1.26 units) in GOLD stage II COPD patients [65].

\section{Quality of life}

Regarding quality of life, in the UPLIFT study, the authors observed an improvement in health status measured by the SGRQ at all time points in the tiotropium group ( $p \leq$ 0.006 for all time points) [66]. In the TORCH study, GOLD II COPD patients also experienced a better health status when treated with SFC in comparison with placebo (change in the SGRQ - 2.3), although the minimal clinically important difference was not reached [67]. The combination of tiotropium/olodaterol showed a greater improvement, with a change from baseline in the SGRQ score of -4.7 compared with -2.2 in the tiotropium arm, and -0.7 in the placebo arm in GOLD II patients [64].

\section{Exacerbations}

The effects of treatment on exacerbation prevention in moderate COPD have been demonstrated in several studies. Tiotropium has shown to prevent exacerbations in patients with less severe COPD. In the MISTRAL study, the number of exacerbations in the subgroup of patients with a FEV1 $\geq 50 \%$ was lower for those receiving tiotropium compared to placebo (1.21 versus 1.97 , respectively; $p<0.01$ ) [68]. The UPLIFT study also showed that the time to the first exacerbation and the time to exacerbation resulting in hospital admission were longer in the tiotropium group than in the control group in the GOLD II subgroup (hazard ratio 0.82 , 95\% CI 0.75-0.90, and $0.74,0.62-0.88$, respectively) [66]. In PC, patients with $\mathrm{FEV} 1>50 \%$ that received tiotropium in addition to their usual treatment were less likely to have $\geq 1$ exacerbation during follow-up compared to the placebo group (6.8\% versus $16.8 \%$ ) [62].

Treatment with SFC has also demonstrated to reduce the annual rate of exacerbations by $31 \%$ in GOLD stage II COPD patients compared with placebo (mean of $0.57 /$ year versus $0.82 /$ year, respectively) [68]. The combination LABA/LAMA is also effective in reducing exacerbations. In fact, the superiority of indacaterol/glycopyrronium over monotherapies and LABA/ICS was demonstrated in several phase III clinical trials, including the FLAME study, which showed that this combination was superior to SFC in reducing the annual rate of exacerbations, although in patients with moderate COPD the difference did not reach significance, probably due to an insufficient sample size of patients with this level of severity (HR $0.93(0.82-1.06)$ ) [69].

These studies suggest that in general, treatment of mild to moderate COPD should be started with one or a combination of two LABD. The only exception would be asthma-COPD overlap (ACO) patients, who usually have more respiratory symptoms, but especially a better response to ICS [70].

\section{Impact of early treatment on the natural history of COPD}

Since the decline in lung function is faster in early stages of the disease, early intervention is required to prevent functional impairment [71]. However, there are only a few large-scale clinical trials on long-term interventions in patients in early stages of COPD. The Lung Health Study, carried out in 3926 smokers with mild to moderate airway obstruction for a period of 5 years showed that participants who stopped smoking experienced an improvement in FEV1 in the year after quitting (average of $47 \mathrm{ml}$ or $2 \%$ ), and that the subsequent rate of decline in FEV1 among sustained quitters was half the rate of that of continuing smokers (31 ml versus $62 \mathrm{ml}$, respectively), and comparable to that of never-smokers [72]. A post hoc analysis of the UPLIFT study that included only GOLD II patients observed that the rate of decline for postbronchodilator FEV1 was lower in the tiotropium group than in the control group (43 ml per year [SE 2] vs. $49 \mathrm{ml}$ per year [SE 2], $p=0.024$ ) [66]. Another sub-analysis from UPLIFT assessed the efficacy of treatment with tiotropium in patients without previous maintenance treatment (naïve patients) and included a majority of GOLD II (60\%). The annual FEV1 decline was slower in the tiotropium group (35 $\mathrm{ml}$ (SD 3) in the tioptropium arm vs. $45 \mathrm{ml}$ (SD 4) in the placebo arm) [73].

More recently, in a randomised placebo-controlled trial which included 841 mild to moderate COPD patients, Zhou et al. [74] observed that the annual FEV1 decline in early stage COPD was lower in patients treated with tiotropium $(29 \mathrm{ml} \pm 5)$ than in the placebo group $(51 \mathrm{ml} \pm 6$; difference $22 \mathrm{ml}$ (95\% CI 6 to 37). In the TORCH study, SFC also showed a reduction in the rate of decline in FEV1 versus placebo in the GOLD II group (difference $16 \mathrm{ml} /$ year, 95\% CI: 0, 32) [63]. These results were confirmed in the SUMMIT study, in which GOLD II patients also had a lower rate of decline in FEV1 in the fluticasone furoate/vilanterol arm compared to placebo (38 $\mathrm{ml}(2.4)$ vs. $-46 \mathrm{ml}(2.5)$ respectively, $p=0.019)$ [75]. These results should be considered in the context of both studies failing to reach their primary outcome of mortality (Table 3 ).

With regard to mortality, the TORCH study showed a $33 \%$ reduction in the risk of death in GOLD stage II COPD patients (HR 0.67; 95\% CI: 0.45, 0.98) with SFC compared with placebo [63]. In UPLIFT, there was a non significant reduction in mortality with tiotropium compared to placebo (hazard ratio [HR], 0.89; 95\% CI, 0.79 to $1.02, p=0.09$ ) [76]. More recently, treatment with fluticasone furoate/vilanterol showed no effect on mortality in COPD patients with FEV1 $>50 \%$ and cardiovascular risk (HR 0.88 [95\% CI 0.74-1.04]; 12\% relative reduction; $p=0.137$ ) [77]. 
Table 3 Impact of early pharmacological treatment on rate of FEV1 decline

\begin{tabular}{|c|c|c|c|c|}
\hline Study & Participants & Follow-up & Intervention & Outcome \\
\hline Scanlon PD et al. [72] & 3926 smokers & 5 years & Quitting smoking & Improvement in FEV1 (47 $\mathrm{ml}$ or $2 \%)$ \\
\hline Decreamer M, et al. [66] & 2375 GOLD ॥ & 4 years & Tiotropium vs. placebo & $\begin{array}{l}\text { Reduction in rate of FEV1 decline } \\
(43 \mathrm{ml} / \text { year vs. } 49 \mathrm{ml} / \text { year, } p=0.024 \text { ) }\end{array}$ \\
\hline Troosters T et al. [73] & 120 GOLD ॥ & 4 years & Tiotropium vs. placebo & $\begin{array}{l}\text { Reduction in rate of FEV1 decline } \\
(35 \mathrm{ml} \text { vs. } 45 \mathrm{ml})\end{array}$ \\
\hline Zhou Y et al. [74] & 841 GOLD I and II & 2 years & Tiotropium vs. placebo & $\begin{array}{l}\text { Reduction in rate of FEV1 decline } \\
(29 \mathrm{ml} \text { vs. } 51 \mathrm{ml})\end{array}$ \\
\hline Jenkins CR et al. [63] & 2156 GOLD ॥ & 3 years & SFC vs. placebo & $\begin{array}{l}\text { Reduction in rate of FEV1 decline } \\
\text { (difference } 16 \mathrm{ml} / \text { year, } 95 \% \mathrm{Cl} 0,32 \text { ) }\end{array}$ \\
\hline Calverley PMA, et al. [75] & 6981 GOLD ॥ & 15 to 44 months & SFC vs. placebo & $\begin{array}{l}\text { Reduction in rate of FEV1 decline } \\
(38 \mathrm{ml} \text { vs }-46 \mathrm{ml}, p=0.019))\end{array}$ \\
\hline
\end{tabular}

FEV1 forced expiratory volume in one second, SFC salmeterol/fluticasone fixed dose combination

\section{Deterioration prevention}

Improvement of clinical and/or spirometric parameters are the endpoints routinely assessed to evaluate the effects of treatments in COPD in most RCTs. However, many patients do not improve and suffer progressive deterioration of their disease. Taking into account that deterioration of lung function, exacerbation frequency, and health status are important parameters to reflect the impact of treatment on COPD management [32, 78-81], the evaluation of composite endpoints may be more sensitive than individual measures to the effects of therapeutic interventions. One of the proposed composite endpoints is the so-called clinically important deterioration (CID). This endpoint allows assessing the rate of deterioration of lung function, exacerbation rate and/or health status of the patient and evaluates the effects of treatment. In addition, this composite endpoint is consistent with the current GOLD strategy, which recommends that lung function, COPD exacerbation risk, and health status are considered when assessing disease progression and severity [3].

A post hoc pooled analysis of three RCTs assessed short-term CID in maintenance-naïve patients with COPD receiving the combination of umeclidinium and vilanterol(LAMA/LABA) compared with tiotropium for 6 months [82].The results showed that early use of dual-bronchodilator therapy has superior efficacy in lung function and may reduce the risk of short-term CID compared to monotherapy in symptomatic patients with COPD [82].

Another analysis described the effect of the combination of another LAMA/LABA, indacaterol/glycopirronium versus both tiotropium or SFC on the prevention of CID using patient data from three large phase 3 RCTs [83]. The study used two different definitions for CID: definition 1 was a composite of $\geq 100 \mathrm{ml}$ decrease in FEV1, a $\geq 4$-unit increase in SGRQ, and a moderate to severe COPD exacerbation, while for definition 2 , the FEV1 component was replaced by $\mathrm{a} \geq 1$-unit decrease in the TDI. This analysis confirmed the utility of the CID endpoint as a measurement of COPD worsening in patients with moderate to severe COPD and using this endpoint the analysis showed that the combination of indacaterol/glycopyrronium offers significant benefits over treatment with a LAMA or a LABA/ICS both in terms of the incidence and time to CID.

Another post hoc analysis evaluated CID using data from two randomised phase III studies that assessed the efficacy and safety of the combination of aclidinium/formoterol in patients with COPD [84]. The results demonstrated that this combination reduced the risk of a first CID, providing greater airway stability, and therefore, fewer deteriorations in lung function, dyspnoea, risk of exacerbations, and health status compared with placebo or monotherapies.

\section{Current treatment guidelines}

A recent review of COPD treatment guidelines published in Europe and Russia in the last 7 years found that although there were differences in some recommended treatments, there was a general agreement on treatment goals and the use of LABD as the cornerstone of COPD treatment [85].

The GOLD strategy establishes pharmacologic treatment algorithms by groups of different risk and intensity of symptoms. For patients in GOLD group A (low risk and low symptom burden), a bronchodilator should be offered to reduce breathlessness. For patients in GOLD group B (low risk and high symptom burden), the preferred initial therapy should be a LABD. If the symptoms persist, therapy with two bronchodilators may be considered [3].

The National Institute for Health and Care Excellence (NICE) guidelines updated in 2010 recommended that patients with FEV1 $>50 \%$ predicted with exacerbations or persistent airflow obstruction should be offered LABDs, and in the case of persistence of symptoms, patients should receive either LABA/ICS or LAMA/LABA [86]. 
The Spanish COPD guidelines (GesEPOC) were developed based on risk stratification and clinical phenotypes [51]. They use an easy risk classification (low or high risk) based on lung function, dyspnoea grade, and history of exacerbations. The four clinical phenotypes identified were: non-exacerbator, ACO, exacerbator with emphysema, and exacerbator with chronic bronchitis. However, they only recommend the determination of clinical phenotype in high-risk patients. Pharmacological recommendations for low-risk patients consist of LABD without any type of anti-inflammatory treatment, and the initial treatment for most high risk patients consists of LAMA/LABA [51].

The newest position statement of the Canadian Thoracic Society in COPD gives more weight to symptoms and exacerbations when it comes to increasing or decreasing therapy. In symptomatic patients with stable COPD without frequent exacerbations, treatment should be started with a LABD, and if experiencing persistent or increased dyspnoea, exercise intolerance, and/or reduced health status despite the use of monotherapy, patients should be considered for "step up" treatment with a LAMA/LABA. In patients with stable COPD experiencing exacerbations despite the use of LAMA or LABA monotherapy, "step up" treatment with inhaled LAMA/ LABA should be considered. If a patient is still experiencing exacerbations despite the use of LAMA/LABA, "step up" treatment with LAMA plus LABA/ICS can be considered. Since inhaled triple or dual therapy may not prove to be superior in every patient, the notion of "step down" treatment may be a consideration in some patients. For patients with suspected ACO, a combination of LABA/ICS is recommended [87]. Figure 1 presents a treatment algorithm for mild-moderate COPD patients.

\section{Conclusions}

Although patients with mild to moderate disease represent the majority of patients with COPD, most studies and in particular RCTs are focused on severe COPD patients. Moreover, mild to moderate patients tend to be underdiagnosed and undertreated, affecting their prognosis and quality of life. Since COPD is progressive, it is important to identify and treat patients at early stages in order to prevent further deterioration, even more considering that patients with mild COPD already have measurable physiological impairment that leads to changes in lifestyle and deconditioning.

Smoking cessation, management of symptoms and treating activity limitations and exacerbations by appropriate pharmacologic and non-pharmacologic management at the earliest possible stage could positively affect the impact and progression of the disease, symptoms, exacerbations, and quality of life. These benefits may be more evident in milder patients than in COPD individuals with a more established disease. Non-pharmacological management includes regular physical activity, pulmonary rehabilitation, an adequate nutrition status, and management of comorbidities, and vaccination against pneumococcal and influenza viruses is also recommended for all patients. On the other hand, early treatment with one LABD or the combination of two bronchodilators has shown to produce a slightly greater

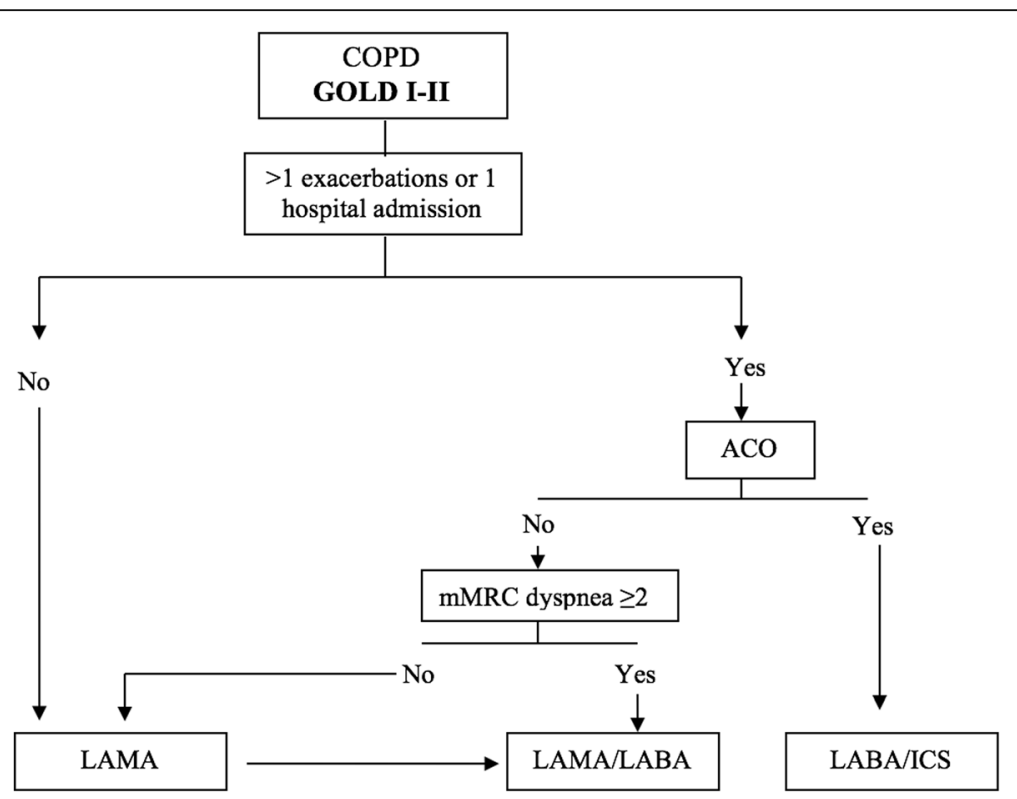

Fig. 1 Proposal of treatment algorithm for the management of GOLD 1-2 COPD patients. COPD: chronic obstructive pulmonary disease; ACO: asthma-COPD overlap; LAMA: long acting anti muscarinic; LABA: long acting b-2 agonists; ICS: inhaled corticosteroids 
improvement in lung function in patients with GOLD stage II than in those with more advanced stages of COPD, and this improvement was associated with an improvement of symptoms, health-related quality of life and a reduction in the risk of exacerbations.

New studies suggest that early treatment with dual bronchodilators may prevent disease deterioration, but this interesting concept should be tested in large clinical trials specifically designed for this objective.

\begin{abstract}
Abbreviations
CAT: COPD Assessment Test; CID: Clinically important deterioration; COPD: Chronic obstructive pulmonary disease; FEV1: Forced expiratory volume in the first second; GOLD: Global Initiative for Chronic Obstructive Lung Disease; ICS: Inhaled corticosteroids; LABA: Long-acting $\beta$-2 agonist; LABD: Long-acting bronchodilator; LAMA: Long-acting antimuscarinic agent; MRC: Medical Research Council; PC: Primary care; RCT: Randomised clinical trial; SABA: Short-acting $\beta$-agonists; SABD: Short-acting bronchodilators; SF12: 12-item short form survey; SFC: Salmeterol/fluticasone combination;
\end{abstract} SGRQ: St. George's Respiratory Questionnaire; TDI: Transition dyspnoea index

\section{Acknowledgements}

Miriam Barrecheguren is the recipient of a Rio Hortega contract in the 2017 Strategic Action Health Call from the Instituto de Salud Carlos III for the years 2018-2019

\section{Funding}

This work has been funded by an unrestricted grant from Laboratorios Esteve S.A. (Barcelona, Spain). The funding body did not participate in any stage of the preparation of the manuscript.

\section{Authors' contributions}

$\mathrm{MM}, \mathrm{MB}$ and $\mathrm{CG}$ have contributed equally to the development of the manuscript. All authors read and approved the final manuscript.

\section{Ethics approval and consent to participate}

Not applicable

\section{Consent for publication}

Not applicable

\section{Competing interests}

Marc Miravitlles has received speaker fees from Boehringer Ingelheim, Chiesi, Cipla, Menarini, Rovi, Grifols and Novartis, and consulting fees from Boehringer Ingelheim, Chiesi, GlaxoSmithKline, Gebro Pharma, CSL Behring, Novartis and Grifols.

Cruz González has received speaker fees from Novartis, Astra, Boehringer Ingelheim, Chiesi, Menarini, and Rovi, and consulting fees from Astra, Boehringer Ingelheim, Novartis and Esteve.

Miriam Barrecheguren has received speaker fees from Grifols and Menarini, and consulting fees from GlaxoSmithKline.

\section{Publisher's Note}

Springer Nature remains neutral with regard to jurisdictional claims in published maps and institutional affiliations.

\section{Author details}

'Pneumology Department, Hospital General Universitari Vall d'Hebron, CIBER de Enfermedades Respiratorias (CIBERES), P. de la Vall d'Hebron, 119-129, 08035 Barcelona, Spain. ${ }^{2}$ Pneumology Department, Hospital Clínic Universitari, Valencia, Spain.

Received: 23 June 2018 Accepted: 5 September 2018 Published online: 17 September 2018

\section{References}

1. Decramer M, Janssens W, Miravitlles M. Chronic obstructive pulmonary disease. Lancet. 2012;379(9823):1341-51.
2. Buist AS, McBurnie MA, Vollmer WM, Gillespie $S$, Burney $P$, Mannino DM, et al. International variation in the prevalence of COPD (the BOLD study): a population-based prevalence study. Lancet. 2007;370(9589):741-50.

3. Vogelmeier CF, Criner GJ, Martínez FJ, Anzueto A, Barnes PJ, Bourbeau J, et al. Global strategy for the diagnosis, management, and prevention of chronic obstructive lung disease 2017 report: GOLD executive summary. Arch Bronconeumol. 2017;53:128-49.

4. Van Remoortel H, Hornikx M, Demeyer H, Langer D, Burtin C, Decramer M, et al. Daily physical activity in subjects with newly diagnosed COPD. Thorax. 2013;68(10):962-3.

5. Elbehairy AF, Ciavaglia CE, Webb KA, Guenette JA, Jensen D, Mourad SM, et al. Pulmonary gas exchange abnormalities in mild chronic obstructive pulmonary disease. Implications for dyspnea and exercise intolerance. Am J Respir Crit Care Med. 2015;191(12):1384-94.

6. Buist AS, Vollmer WM, McBurnie MA. Worldwide burden of COPD in highand low-income countries. Part I. the burden of obstructive lung disease (BOLD) initiative. Int J Tuberc Lung Dis. 2008:12(7):703-8.

7. Bernd L, Joan BS, Michael S, Bernhard K, Lowie EV, Louisa G, et al. Determinants of underdiagnosis of COPD in national and international surveys. Chest. 2015;148(4):971-85.

8. Kruis AL, Ställberg B, Jones RC, Tsiligianni IG, Lisspers K, van der Molen T, et al. Primary care COPD patients compared with large pharmaceuticallysponsored COPD studies: an UNLOCK validation study. PLoS One. 2014;9(3): e90145.

9. Maltais F, Dennis N, Chan CK. Rationale for earlier treatment in COPD: a systematic review of published literature in mild-to-moderate COPD. COPD. 2013;10(1):79-103.

10. Narsingam S, Bozarth AL, Abdeljalil A. Updates in the management of stable chronic obstructive pulmonary disease. Postgrad Med. 2015;127(7):758-70.

11. Kannan RR, Singh N, Przekwas A. A quasi-3D compartmental multi-scale approach to detect and quantify diseased regional lung constriction using spirometry data. Int J Numer Method Biomed Eng. 2018;34:e2973.

12. Vos T, Flaxman AD, Naghavi M, Lozano R, Michaud C, Ezzati M, et al. Years lived with disability (YLDs) for 1160 sequelae of 289 diseases and injuries 1990-2010: a systematic analysis for the global burden of disease study 2010. Lancet. 2012:380:2163-96.

13. Halbert RJ, Natoli JL, Gano A, Badamqarav E, Buist AS, Mannino DM. Global burden of COPD: systematic review and meta-analysis. Eur Respir J. 2006;28: 523-32.

14. Adeloye D, Chua S, Lee C, Basquill C, Papana A, Theodoratou E, et al. Global and regional estimates of COPD prevalence: systematic review and metaanalysis. J Glob Health. 2015;5(2):020415.

15. Menezes AM, Perez-Padilla R, Jardim JR, Muiño A, López MV, Valdivia G, et al. Chronic obstructive pulmonary disease in five Latin American cities (the PLATINO study): a prevalence study. Lancet. 2005;366(9500):1875-81.

16. Atsou K, Chouaid C, Hejblum G. Variability of the chronic obstructive pulmonary disease key epidemiological data in Europe: systematic review. BMC Med. 2011;9:7.

17. Peña VS, Miravitlles M, Gabriel R, Jiménez-Ruiz CA, Villasante C, Masa JF, et al. Geographic variations in prevalence and underdiagnosis of COPD: results of the IBERPOC multicentre epidemiological study. Chest. 2000; 118(4):981-9.

18. Miravitlles M, Soriano JB, García-Río F, Munoz L, Durán-Tauleria E, Sánchez G, et al. Prevalence of COPD in Spain: impact of undiagnosed COPD on quality of life and daily life activities. Thorax. 2009;64(10):863-8.

19. Soriano JB, Ancochea J, Miravitlles M, García-Río F, Duran-Tauleria E, Muñoz $L$, et al. Recent trends in COPD prevalence in Spain: a repeated crosssectional survey 1997-2007. Eur Respir J. 2010;36(4):758-65.

20. Llordés M, Jaén Á, Almagro P, Heredia JL, Morera J, Soriano JB, et al. Prevalence, risk factors and diagnostic accuracy of COPD among smokers in primary care. COPD. 2015;12(4):404-12.

21. Llordés M, Zurdo E, Jaén Á, Vázquez I, Pastrana L, Miravitlles M. Which is the best screening strategy for COPD among smokers in primary care? COPD. 2017;14(1):43-51.

22. Almagro P, Soriano J. Under diagnosis in COPD: a battle worth fighting. Lancet Respir Med. 2017;5(5):367-8.

23. Ulrik CS, Lokke A, Dahl R, Dollerup J, Hansen G, Cording PH, Andersen KK. Early detection of COPD in general practice. Int J COPD. 2011;6:123-7.

24. Thorat YT, Salvo SS, Kodgule RR. Peak flow meter with a questionnaire and mini-spirometer to help detect asthma and COPD in real-life clinical practice: a cross-sectional study. NPJ Prim Care Respir Med. 2017;27:32. 
25. Price DB, Tinkelman DG, Halbert RJ, Nordyke RJ, Isonaka S, Nonikov D, et al. Symptom-based questionnaire for identifying COPD in smokers. Respir Int Rev Thorac Dis. 2006;73(3):285-95.

26. Karrasch S, Bruske I, Smith MP, Thorand B, Huth C, Ladwig KH, et al. What is the impact of different spirometric criteria on the prevalence of spirometrically defined COPD and its comorbidities? Results from the population-based KORA study. Int J Chron Obstruct Pulmon Dis. 2016;11:1881-94.

27. Lung Health Study Research Group, Wise R, Connett J, Weinmann G, Scanlon P, Skeans M. Effect of inhaled triamcinolone on the decline in pulmonary function in chronic obstructive pulmonary disease. N Engl J Med. 2000;343(26):1902-9.

28. Tantucci C, Modina D. Lung function decline in COPD. Int J Chron Obstruct Pulmon Dis. 2012:7:95-9.

29. Kim J, Yoon HI, Oh YM, Lim SY, Lee JH, Kim TH, et al. Lung function decline rates according to GOLD group in patients with chronic obstructive pulmonary disease. Int J Chron Obstruct Pulmon Dis. 2015;10:1819-27.

30. Bhatt SP, Soler X, Wang X, Murray S, Anzueto AR, Beaty TH, et al. Association between functional small airway disease and FEV1 decline in chronic obstructive pulmonary disease. Am J Respir Crit Care Med. 2016;194(2):178-84.

31. Dransfield MT, Kunisaki KM, Strand MJ, Anzueto A, Bhatt SP, Bowler RP, et al. Acute exacerbations and lung function loss in smokers with and without chronic obstructive pulmonary disease. Am J Respir Crit Care Med. 2017; 195(3):324-30.

32. Donaldson GC, Seemungal TA, Bhowmik A, Wedzicha JA. Relationship between exacerbation frequency and lung function decline in chronic obstructive pulmonary disease. Thorax. 2002;57(10):847-52.

33. Miravitlles M, Ferrer M, Pont A, Zalacain R, Álvarez-Sala JL, Masa F, et al. Effect of exacerbations on quality of life in patients with chronic obstructive pulmonary disease: a 2 year follow up study. Thorax. 2004;59(5):387-95.

34. Soler-Cataluña JJ, Martínez-García MA, Roman Sánchez P, Salcedo E, Navarro M, Ochando R. Severe acute exacerbations and mortality in patients with chronic obstructive pulmonary disease. Thorax. 2005;60(11):925-31.

35. Miravitlles M, Ribera A. Understanding the impact of symptoms on the burden of COPD. Respir Res. 2017;18:67.

36. Miravitlles M, Menezes A, Lopez Varela MV, Casas A, Ugalde L, RamírezVenegas $A$, et al. Prevalence and impact of respiratory symptoms in a population of patients with COPD in Latin America: the LASSYC observational study. Respir Med. 2018;134:62-9.

37. Miravitlles M, Worth H, Soler Cataluña JJ, Price D, De Benedetto F, Roche N, et al. Observational study to characterise 24-hour COPD symptoms and their relationship with patient-reported outcomes: results from the ASSESS study. Respir Res. 2014;15:122.

38. Bridevaux PO, Gerbase MW, Probst-Hensch NM, Schindler C, Gaspoz JM, Rochat T. Long-term decline in lung function, utilisation of care and quality of life in modified GOLD stage 1 COPD. Thorax. 2008:63(9):768-74.

39. Rennard SI, Drummond MB. Early chronic obstructive pulmonary disease: definition, assessment, and prevention. Lancet. 2015;385(9979):1778-88.

40. Chen C, Jian W, Gao Y, Xie Y, Song Y, Zheng J. Early COPD patients with lung hyperinflation associated with poorer lung function but better bronchodilator responsiveness. Int J Chron Obstruct Pulmon Dis. 2016;11: 2519-26.

41. Anzueto A, Miravitlles M. Pathophysiology of dyspnea in COPD. Postgrad Med. 2017;129(3):366-74

42. Fabricius P, Lokke A, Marott $J$, Vestbo J, Lange P. Prevalence of COPD in Copenhagen. Respir Med. 2011;105(3):410-7.

43. Jones PW, Brusselle G, Dal Negro RW, Ferrer M, Kardos P, Levy ML, et al. Health-related quality of life in patients by COPD severity within primary care in Europe. Respir Med. 2011;105(1):57-66.

44. Mullerova H, Lu C, Li H, Tabberer M. Prevalence and burden of breathlessness in patients with chronic obstructive pulmonary disease managed in primary care. PLoS One. 2014;9(1):e85540.

45. Nishimura K, Izumi T, Tsukino M, Oga T. Dyspnea is a better predictor of 5year survival than airway obstruction in patients with COPD. Chest. 2002 121(5):1434-40.

46. Ramón MA, Esquinas C, Barrecheguren M, Pleguezuelos E, Molina J, Quintano JA, et al. Self-reported daily walking time in COPD: relationship with relevant clinical and functional characteristics. Int J Chron Obstruct Pulmon Dis. 2017;12:1173-81.

47. Waschki B, Kirsten A, Holz O, Muller KC, Meyer T, Watz H, et al. Physical activity is the strongest predictor of all-cause mortality in patients with COPD: a prospective cohort study. Chest. 2011;140(2):331-42.
48. Van Remoortel H, Hornikx M, Langer D, Burtin C, Everaerts S, Verhamme P, et al. Risk factors and comorbidities in the preclinical stages of chronic obstructive pulmonary disease. Am J Respir Crit Care Med. 2014;189(1):30-8.

49. García-Aymerich J, Lange P, Benet M, Schnohr P, Anto JM. Regular physical activity reduces hospital admission and mortality in chronic obstructive pulmonary disease: a population based cohort study. Thorax. 2006;61(9):772-8.

50. Pitta F, Troosters T, Spruit MA, Probst VS, Decramer M, Gosselink R. Characteristics of physical activities in daily life in chronic obstructive pulmonary disease. Am J Respir Crit Care Med. 2005;171(9):972-7.

51. Miravitlles M, Soler-Cataluña JJ, Calle M, Molina J, Almagro P, Quintano JA, et al. Spanish guidelines for Management of Chronic Obstructive Pulmonary Disease (GesEPOC) 2017. Pharmacological treatment of stable phase. Arch Bronconeumol. 2017;53(6):324-35.

52. Price D, Freeman D, Cleland J, Kaplan A, Cerasoli F. Earlier diagnosis and earlier treatment of COPD in primary care. Prim Care Respir J. 2011;20(1):15-22.

53. Puhan MA, Gimeno-Santos E, Scharplatz M, Troosters T, Walters EH, Steurer J. Pulmonary rehabilitation following exacerbations of chronic obstructive pulmonary disease. Cochrane Database Syst Rev. 2011;10:CD005305.

54. Corhay JL, Dang DN, Van Cauwenberge H, Louis R. Pulmonary rehabilitation and COPD: providing patients a good environment for optimizing therapy. Int J Chron Obstruct Pulmon Dis. 2014;9:27-39.

55. Jacome CIO, Marques ASPD. Pulmonary rehabilitation for mild chronic obstructive pulmonary disease: a systematic review. Respir Care. 2014 Apr; 59:588-94.

56. Price D, West D, Brusselle G, Gruffydd-Jones K, Jones R, Miravitlles M, et al. Management of COPD in the UK primary-care setting: an analysis of real-life prescribing patterns. Int J Chron Obstruct Pulmon Dis. 2014;9:889-904.

57. Wurst KE, Shukla A, Muellerova H, Davis KJ. Respiratory pharmacotherapy use in patients newly diagnosed with chronic obstructive pulmonary disease in a primary care setting in the UK: a retrospective cohort study. COPD. 2014;11(5):521-30.

58. Raluy-Callado M, Lambrelli D, MacLachlan S, Khalid JM. Epidemiology, severity, and treatment of chronic obstructive pulmonary disease in the United Kingdom by GOLD 2013. Int J Chron Obstruct Pulmon Dis. 2015;10: 925-37

59. Barrecheguren M, Monteagudo M, Ferrer J, Borrell E, Llor C, Esquinas C, et al. Treatment patterns in COPD patients newly diagnosed in primary care. A population-based study. Respir Med. 2016;111:47-53.

60. Langsetmo L, Platt RW, Ernst P, Bourbeau J. Underreporting exacerbation of chronic obstructive pulmonary disease in a longitudinal cohort. Am J Respir Crit Care Med. 2008;177:396-401.

61. Beeh KM, Beier J, Buhl R, Stark-Lorenzen P, Gerken F, Metzdorf N, et al. Efficacy of tiotropium bromide (Spiriva) in patients with chronic-obstructive pulmonary disease (COPD) of different severities. Pneumologie. 2006;60(6):341-6.

62. Freeman D, Lee A, Price D. Efficacy and safety of tiotropium in COPD patients in primary care--the SPiRiva usual CarE (SPRUCE) study. Respir Res. 2007:8:45.

63. Jenkins CR, Jones PW, Calverley PM, Celli B, Anderson JA, Ferguson GT, et al. Efficacy of salmeterol/fluticasone propionate by GOLD stage of chronic obstructive pulmonary disease: analysis from the randomised, placebocontrolled TORCH study. Respir Res. 2009;10:59.

64. Singh D, Gaga M, Schmidt O, Bjermer L, Gronke L, Voss F, et al. Effects of tiotropium + olodaterol versus tiotropium or placebo by COPD disease severity and previous treatment history in the OTEMTO(R) studies. Respir Res. 2016;17(1):73.

65. Vogelmeier CF, Gaga M, Aalamian-Mattheis M, Greulich T, Marin JM, Castellani W, et al. Efficacy and safety of direct switch to indacaterol/ glycopyrronium in patients with moderate COPD: the CRYSTAL open-label randomised trial. Respir Res 2017;18(1):140.

66. Decramer M, Celli B, Kesten S, Lystig T, Mehra S, Tashkin DP, et al. Effect of tiotropium on outcomes in patients with moderate chronic obstructive pulmonary disease (UPLIFT): a prespecified subgroup analysis of a randomised controlled trial. Lancet. 2009;374(9696):1171-8.

67. Jones PW, Anderson JA, Calverley PMA, Celli BR, Ferguson GT, Jenkins C, et al. Health status in the TORCH study of COPD: treatment efficacy and other determinants of change. Respir Res. 2011;12(1):71.

68. Dusser D, Bravo ML, lacono P. The effect of tiotropium on exacerbations and airflow in patients with COPD. Eur Respir J. 2006;27(3):547-55.

69. Wedzicha JA, Banerji D, Chapman KR, Vestbo J, Roche N, Ayers RT, et al. Indacaterol-Glycopyrronium versus salmeterol-fluticasone for COPD. N Engl J Med. 2016;374(23):2222-34 
70. Barrecheguren M, Esquinas C, Miravitlles M. The asthma-chronic obstructive pulmonary disease overlap syndrome (ACOS): opportunities and challenges. Curr Opin Pulm Med. 2015 Jan;21(1):74-9.

71. Decramer M, Miravitlles M, Price D, Román-Rodríguez M, Llor C, Welte T, et al. New horizons in early stage COPD - improving knowledge, detection and treatment. Respir Med. 2011;105:1576-87.

72. Scanlon PD, Connett JE, Waller LA, Altose MD, Bailey WC, Buist AS, et al. Smoking cessation and lung function in mild-to-moderate chronic obstructive pulmonary disease. The lung health study. Am J Respir Crit Care Med. 2000;161(2 Pt 1):381-90.

73. Troosters T, Celli B, Lystig T, Kesten S, Mehra S, Tashkin DP, et al. Tiotropium as a first maintenance drug in COPD: secondary analysis of the UPLIFT trial. Eur Respir J. 2010;36(1):65-73.

74. Zhou Y, Zhong NS, Li X, Chen S, Zheng J, Zhao D, et al. Tiotropium in early-stage chronic obstructive pulmonary disease. N Engl J Med. 2017;377(10):923-35.

75. Calverley PMA, Anderson JA, Brook RD, Crim C, Gallot N, Kilbride S, et al. SUMMIT (study to understand mortality and morbidity) investigators. Fluticasone Furoate, Vilanterol, and Lung Function Decline in Patients with Moderate Chronic Obstructive Pulmonary Disease and Heightened Cardiovascular Risk. Am J Respir Crit Care Med. 2018;197(1):47-55.

76. Tashkin DP, Celli B, Senn S, Burkhart D, Kesten S, Menjoge S, Decramer M. A 4-year trial of tiotropium in chronic obstructive pulmonary disease. N Engl J Med. 2008;359:1543-54.

77. Vestbo J, Anderson JA, Brook RD, Calverley PM, Celli BR, Crim C, et al. Fluticasone furoate and vilanterol and survival in chronic obstructive pulmonary disease with heightened cardiovascular risk (SUMMIT): a doubleblind randomised controlled trial. Lancet. 2016;387(10030):1817-26.

78. Celli BR, Thomas NE, Anderson JA, Ferguson GT, Jenkins CR, Jones PW, et al. Effect of pharmacotherapy on rate of decline of lung function in chronic obstructive pulmonary disease: results from the TORCH study. Am J Respir Crit Care Med. 2008;178(4):332-8.

79. Spencer S, Calverley PM, Sherwood Burge P, Jones PW. Isolde study group inhaled steroids in obstructive lung disease. Health status deterioration in patients with chronic obstructive pulmonary disease. Am J Respir Crit Care Med. 2001;163(1):122-8.

80. Wilke $\mathrm{S}$, Jones PW, Mullerova $\mathrm{H}$, Vestbo J, Tal-Singer $\mathrm{R}$, Franssen FM, et al. One-year change in health status and subsequent outcomes in COPD. Thorax. 2015;70(5):420-5.

81. Anzueto A. Impact of exacerbations on COPD. Eur Respir Rev. 2010;19(116): 113-8.

82. Maleki-Yazdi MR, Singh D, Anzueto A, Tombs L, Fahy WA, Naya I. Assessing short-term deterioration in maintenance-naive patients with copd receiving umeclidinium/vilanterol and tiotropium: a pooled analysis of three randomized trials. Adv Ther. 2017;33(12):2188-99.

83. Anzueto AR, Vogelmeier CF, Kostikas K, Mezzi K, Fucile S, Bader G, et al. The effect of indacaterol/glycopyrronium versus tiotropium or salmeterol/ fluticasone on the prevention of clinically important deterioration in COPD. Int J Chron Obstruct Pulmon Dis. 2017;12:1325-37.

84. Singh D, D'Urzo AD, Chuecos F, Muñoz A, García GE. Reduction in clinically important deterioration in chronic obstructive pulmonary disease with aclidinium/formoterol. Respir Res. 2017;18(1):106.

85. Miravitlles M, Vogelmeier C, Roche N, Halpin D, Cardoso J, Chuchalin AG, et al. A review of national guidelines for management of COPD in Europe. Eur Respir J. 2016;47(2):625-37.

86. O'Reilly J, Jones MM, Parnham J, Lovibond K, Rudolf M, Guideline Development Group. Management of stable chronic obstructive pulmonary disease in primary and secondary care: summary of updated NICE guidance. BMJ. 2010;340:C3134.

87. Bourbeau J, Bhutani M, Hernandez P, Marciniuk DD, Aaron SD, Balter M, et al. CTS position statement: pharmacotherapy in patients with COPD —an update. Can J Resp Crit Care Sleep Med. 2017;1 (4):222-41.

88. Vincken W, van Noord JA, Greefhorst AP, Bantje TA, Kesten S, Korducki L, et al. Improved health outcomes in patients with COPD during 1 yr's treatment with tiotropium. EurRespir J. 2002;19(2):209-16.

89. Casaburi R, Mahler DA, Jones PW, Wanner A, San PG, ZuWallack RL, et al. A long-term evaluation of once-daily inhaled tiotropium in chronic obstructive pulmonary disease. Eur Respir J. 2002;19(2):217-24.

90. Jones PW, Willits LR, Burge PS, Calverley PM. Inhaled steroids in obstructive lung disease in Europe study investigators. Disease severity and the effect of fluticasone propionate on chronic obstructive pulmonary disease exacerbations. Eur Respir J. 2003;21(1):68-73.

\section{Ready to submit your research? Choose BMC and benefit from:}

- fast, convenient online submission

- thorough peer review by experienced researchers in your field

- rapid publication on acceptance

- support for research data, including large and complex data types

- gold Open Access which fosters wider collaboration and increased citations

- maximum visibility for your research: over $100 \mathrm{M}$ website views per year

At BMC, research is always in progress.

Learn more biomedcentral.com/submissions 